\title{
Using a Machine Learning Algorithm to Predict the Likelihood of Presence of Dental Caries among Children Aged 2 to 7
}

\author{
Francisco Ramos-Gomez ${ }^{1, *}$, Marvin Marcus ${ }^{2}$, Carl A. Maida ${ }^{2,3}$, Yan Wang ${ }^{4}{ }^{(}$, Janni J. Kinsler ${ }^{1}$, Di Xiong ${ }^{2,5} \mathbb{D}^{\text {, }}$ \\ Steve Y. Lee ${ }^{6}$, Ron D. Hays ${ }^{7,8}{ }^{-}$, Jie Shen ${ }^{2}$, James J. Crall ${ }^{2}$ and Honghu Liu ${ }^{2,3,8}$
}

1 Section of Pediatric Dentistry, Division of Growth \& Development, School of Dentistry, University of California, Los Angeles, CA 90095, USA; jnhaiem@dentistry.ucla.edu

2 Division of Public Health \& Community Dentistry, School of Dentistry, University of California, Los Angeles, CA 90095, USA; mmarcus@dentistry.ucla.edu (M.M.); cmaida@dentistry.ucla.edu (C.A.M.); dixiong@g.ucla.edu (D.X.); shenjie@stat.ucla.edu (J.S.); jcrall@dentistry.ucla.edu (J.J.C.); hhliu@dentistry.ucla.edu (H.L.)

3 Division of Oral Biology and Medicine, School of Dentistry, University of California, Los Angeles, CA 90095, USA

4 Division of Infectious Diseases, David Geffen School of Medicine, University of California, Los Angeles, CA 90095, USA; wangyan@ucla.edu

5 Department of Biostatistics, School of Public Health, University of California, Los Angeles, CA 90095, USA

6 Division of Constitutive and Regenerative Sciences, School of Dentistry, University of California, Los Angeles, CA 90095, USA; slee@dentistry.ucla.edu

7 Department of Health Policy and Management, School of Public Health, University of California, Los Angeles, CA 90095, USA; drhays@ucla.edu

check for updates

Citation: Ramos-Gomez, F.; Marcus, M.; Maida, C.A.; Wang, Y.; Kinsler, J.J.; Xiong, D.; Lee, S.Y.; Hays, R.D.; Shen, J.; Crall, J.J.; et al. Using a Machine Learning Algorithm to Predict the Likelihood of Presence of Dental Caries among Children Aged 2 to 7. Dent. J. 2021, 9, 141. https://doi.org/ 10.3390/dj9120141

Academic Editor: Kristina Gorseta

Received: 28 October 2021

Accepted: 21 November 2021

Published: 1 December 2021

Publisher's Note: MDPI stays neutral with regard to jurisdictional claims in published maps and institutional affiliations.

Copyright: () 2021 by the authors. Licensee MDPI, Basel, Switzerland. This article is an open access article distributed under the terms and conditions of the Creative Commons Attribution (CC BY) license (https:// creativecommons.org/licenses/by/ $4.0 /)$.
8 Division of General Internal Medicine and Health Services Research, Department of Medicine, University of California, Los Angeles, CA 90095, USA

* Correspondence: frg@dentistry.ucla.edu; Tel.: +1-(310)-825-9460; Fax: +1-(310)-206-7597

\begin{abstract}
Background: Dental caries is the most common chronic childhood infectious disease and is a serious public health problem affecting both developing and industrialized countries, yet it is preventable in most cases. This study evaluated the potential of screening for dental caries among children using a machine learning algorithm applied to parent perceptions of their child's oral health assessed by survey. Methods: The sample consisted of 182 parents/caregivers and their children 2-7 years of age living in Los Angeles County. Random forest (a machine learning algorithm) was used to identify survey items that were predictors of active caries and caries experience. We applied a three-fold cross-validation method. A threshold was determined by maximizing the sum of sensitivity and specificity conditional on the sensitivity of at least $70 \%$. The importance of survey items to classifying active caries and caries experience was measured using mean decreased Gini (MDG) and mean decreased accuracy (MDA) coefficients. Results: Survey items that were strong predictors of active caries included parent's age (MDG $=0.84 ; \mathrm{MDA}=1.97)$, unmet needs $(\mathrm{MDG}=0.71 ; \mathrm{MDA}=2.06$ ) and the child being African American (MDG $=0.38 ; \mathrm{MDA}=1.92$ ). Survey items that were strong predictors of caries experience included parent's age $(\mathrm{MDG}=2.97 ; \mathrm{MDA}=4.74)$, child had an oral health problem in the past 12 months (MDG $=2.20$; $\mathrm{MDA}=4.04$ ) and child had a tooth that hurt $(\mathrm{MDG}=1.65 ; \mathrm{MDA}=3.84)$. Conclusion: Our findings demonstrate the potential of screening for active caries and caries experience among children using surveys answered by their parents.
\end{abstract}

Keywords: dental caries; children; oral health; disparities; machine learning algorithms; random forest

\section{Introduction}

Dental caries is the most common chronic childhood infectious disease and is a serious public health problem affecting both developing and industrialized countries, yet it is preventable in most cases [1-6]. In the United States (US), the overall prevalence of dental caries has decreased in recent years, but there has been an increase among toddlers and 
preschoolers 5 years old and younger $[4,7,8]$. Early childhood caries (ECC) currently affects $21 \%$ of 2- to 5-year-old US children [9]. If left untreated, dental caries can lead to infections, pain and loss of teeth, and interfere with daily activities like eating, sleeping, learning and playing $[7,10,11]$.

While numerous factors contribute to ECC, such as diet, oral hygiene habits and oral bacteria, it can be prevented with appropriate behavior modifications [4,6-9]. Although oral health education is not the only step in ECC prevention (community water fluoridation and health-promoting oral health policies are equally significant), it is a critical and important step $[7,12]$. Oral health education traditionally falls within the scope of responsibilities of dental providers and public health educators. However, educating parents on how to assess their children's oral health status is crucial to identifying early signs of ECC, such as enamel opacity and high levels of plaque, thus helping to reduce the incidence and prevalence of ECC.

Involving parents in their children's oral health care is more important now than ever as the current COVID-19 pandemic provides an important lesson on how a single event can impact the way in which preventive health care is delivered [13]. During this pandemic, many in-person preventive and non-urgent dental care appointments had to be canceled. While telehealth options were made available, providers had to depend more on parent's assessment of their children's oral health status as they could not do the actual exam themselves. Additionally, the current trend of teledentistry and virtual dental homes will rely less on in-person routine preventive dental visits/screenings to identify problems with children's teeth and more on parents to assess the status of their children's teeth [13]. Thus, understanding parent's knowledge and perceptions of their child's oral health care can provide critical information to oral health providers when in-person visits are not possible.

The authors' previous work showed that several survey items completed by children and their parents were significantly associated with the oral health status index, including items related to perception of dental appearance and physical factors of a child's mouth, such as being pleased/happy with the look and color of the child's teeth, the child having straight versus crooked or crowded teeth and the child having pain in the mouth/teeth [14-16]. This suggests survey items have the potential to be used to assess the oral health status of children when in-person dental screenings are not possible. While these studies and others found that children 8 years and older could accurately report on their own health, infants and young children under the age of 8 must rely on their parents to assess their oral health status [15,17-22].

This study will help fill this gap by utilizing random forest (RF), a machine learning algorithm, to identify the best set of items from the parent's oral health survey that predict the likelihood of the presence of active caries and caries experiences for children between 2 to 7 years of age and conducting a dental exam to document active caries and caries experience to identify decayed teeth, missing teeth, filled teeth and tooth (DMFT) position [23].

\section{Materials and Methods}

\subsection{Sample}

The sample for this paper included 182 parents and their child between 2 and 7 years of age. This is a subsample of a larger study that recruited about 600 adolescents and children between 2 and $<18$ years of age and their parents from August 2015 through October 2019 to develop a set of oral health items to predict oral health status [15]. Parents of all children between 2 and $<18$ years of age and children between 8 and $<18$ years of age completed a survey using Audio Computer Assisted Self-Interview Software (ACASI). Parents and their children were selected from 12 dental care sites throughout Los Angeles County. The sites included community dental clinics, comprehensive health centers and group and solo general and pediatric practices. To obtain a diverse sample, these sites covered different geographic areas and communities, ranging from low-income underserved immigrant neighborhoods to high-income professional communities with diverse racial and ethnic 
compositions. Inclusion criteria for recruitment included that only one child per family could be enrolled in the study. Children in orthodontic treatment were excluded from the study as this would interfere with a dental examination. For the current study, we evaluated survey items answered by the 182 parents of children 2 to 7 years of age (representing 30\% of all participants from the larger study). For a complete description of the methodology, please refer to the authors' previous work. [14,15]. Institutional review board approval for this study was obtained from the University of California, Los Angeles, Office of the Human Research Protection Program (Institutional Review Board approval 13-001330). Written consent was obtained from parents prior to participation. This study conforms to the Strengthening the Reporting of Observational Studies in Epidemiology (STROBE) guidelines for cross-sectional studies [24,25].

\subsection{Data Collection}

Parents completed a 34-item questionnaire using ACASI. The questionnaire included self-reported oral health-related items assessing physical health, mental health and social function domains. The questions were based on the researchers' previous work on the multilevel influences on oral health which integrates the life-course concept into the dynamics of oral health by including genetic, biological, behavioral, social and economic contexts that change as a person develops through childhood, adolescence, young adulthood and later adult life $[15,16,26]$. Specific topic areas for children 2-7 years of age were use of fluoridated tap water and fluoridated toothpaste, access to dental services (including fluoride varnish applications), oral health status, physical characteristics of teeth and gums, general wellbeing, health preventive actions taken by parents for their children, tooth brushing habits, oral hygiene and socio-demographics $[15,16,26]$. Most of the respondents were parents, but in a few cases the respondent was a caregiver such as a grandparent. Our analyses did not distinguish by type of respondent. The questionnaire was only available in English, but Spanish and Chinese translators were available on-site for assistance, if needed. It took parents an average of 20-45 min to complete the questionnaire. Parents were compensated with USD 55 in cash if they completed the questionnaire and the child was screened by a dentist.

Children received clinical examinations prior to or after parents completed the questionnaire. The clinical examination included a full mouth examination of all primary and permanent teeth. It consisted of examining the oral mucosa, teeth for the presence of obvious caries and decalcification (white spots), the presence of plaque on the centrals and molars, when present, and bleeding on probing and inflammation of the gingiva. The dental examiners were two faculty dentists from the UCLA School of Dentistry who underwent training and inter- and intra-rater calibration, which was analyzed using Cohen's kappa. The intra-rater calibration was conducted by duplicate dental examinations on the same child between two dentists. We assessed the intra- and inter-examiners during the training stage at each of the study sites. A total of 51 children received dental exams by both examiners to check the inter-rater reliability. In each study site, 3 children were randomly selected to be checked by the two pediatric dentists, but the same recorder. All the clinical exam measurements were repeated. For active caries (coded as DT), 2 subjects were recorded as having DT (DT $>0$ ) by both examiners and 44 subjects were recorded as having no caries $(\mathrm{DT}=0)$. The percentage agreement that both the examiners identified a child with active caries or not was $88 \%$. However, with an imbalanced distribution of the presence of active caries in our study (13\%), the high agreement did not align with the low kappa (0.39), which is common with an imbalanced distribution of an outcome [27]. In these cases, using percentage agreement between two examiners is appropriate [27]. For caries experience, a total of 23 children with caries experience (DMFT $>0$ ) and another 23 children without caries experience were found by both dental examiners. The percentage agreement between the two examiners was $90 \%$ with a kappa of 0.80 . The results of the dental exams were based on the presence of active caries (DT coded as Yes/No) and the DMFT index which has been evaluated in previous studies with children for caries experi- 
ence [23]. The DMFT/dmft index was coded as 0 for no caries experience and 1 for one or more teeth with decay, missing or with fillings. This includes both primary and permanent teeth. We did not include white spots, crookedness, fracture or abnormal teeth positions.

\subsection{Data Analysis}

We used RF to derive the machine learning algorithm, which is based on a collection of decision trees [28,29]. The decision trees are obtained by searching for variables within the training set and splitting them in such a way that will generate the "best" two subsets $[28,29]$. The goal is to create branches and leaves based on an optimal splitting criterion. Specifically, at every branch or node, a conditional statement classifies the data point based on a fixed threshold in a specific variable, therefore splitting the data. To make predictions, every new instance starts in the root node (top of the tree) and moves along the branches until it reaches a leaf node where no further branching is possible. In prediction, more than one tree is needed to improve the accuracy $[28,29]$. RF is based on the summary statistics of all prediction trees. It is capable of fitting complex datasets and performing both classification and regression tasks [28].

In developing the RF, $70 \%$ of subjects were assigned to a training set and $30 \%$ of subjects to a testing set randomly based on the outcome variables (active caries and caries experience) $[28,29]$. Due to the small sample size and low prevalence of active caries, the models were developed on the training sets using a 3-fold cross-validation method. Cross-validation is a technique used to help tune the parameters using the training set only [28-30]. We divided the training set into 3 folds randomly and equally. For each crossvalidation loop, 2 out of 3 folds were selected as the subtraining set and the remaining fold as the validation set [28-30]. The model is derived from 2 out of the 3 folds and validated on the withholding validation set. It was repeated 3 times so that each fold could be treated as the validation set only once. The results of the 3 validation sets were aggregated together as the training model [28-30]. We derived parameters for each decision tree (mtry), and number of decision trees to grow (ntree) on the best cross-validation aggregated area under the receiver operating characteristic curve (AUC) to obtain the best models. A threshold is determined by maximizing the sum of sensitivity (true positive rate) and specificity (true negative rate) with the condition that sensitivity is at least $70 \%$. The classification performance is evaluated on the testing set [28-30]. Table 1 presents the parameters and performance on cross-validation sets and testing sets separately for active caries and caries experience models.

Table 1. Random forest performance on cross-validation sets and testing sets for active caries and caries experience.

\begin{tabular}{|c|c|c|c|c|c|c|c|c|}
\hline & \multirow[b]{2}{*}{$\begin{array}{c}\text { Tuning } \\
\text { Parameter * }\end{array}$} & \multirow[b]{2}{*}{ Threshold } & \multicolumn{3}{|c|}{ 3-Fold Cross-Validation } & \multicolumn{3}{|c|}{ Test } \\
\hline & & & Accuracy & Sensitivity & Specificity & Accuracy & Sensitivity & Specificity \\
\hline $\begin{array}{l}\text { Active } \\
\text { Caries }\end{array}$ & $\begin{array}{c}\text { mtry }=41 \\
\text { ntree }=100\end{array}$ & 0.08 & 0.71 & 0.94 & 0.68 & 0.62 & 0.57 & 0.63 \\
\hline $\begin{array}{c}\text { Caries } \\
\text { Experience }\end{array}$ & $\begin{array}{c}\text { mtry }=2 ; \\
\text { ntree }=100\end{array}$ & 0.36 & 0.71 & 0.78 & 0.64 & 0.73 & 0.92 & 0.55 \\
\hline
\end{tabular}

* 1. mtry stands for the number of variables for each tree; 2 . ntree stands for the number of total trees to grow; 3 . threshold is used to classify the instances into two groups.

The importance of the questionnaire items in classifying the different oral health status was measured by the mean decreased accuracy (MDA) and the mean decreased Gini coefficient (MDG) $[29,30]$. The MDA refers to the reduced accuracy in classification by excluding the corresponding questionnaire item. MDA is calculated on the dataset by randomly shuffling the data for that particular item and then subtracting the two accuracies (i.e., before and after shuffling). The MDG was defined by the consistency of classification by the corresponding questionnaire item. MDG decrease is calculated based on the mean decrease in Gini (i.e., pi $(i-p i))$ each time when the tree is split on that item. The value is 
sometimes higher because the $r$ package weights the impurities by the raw counts, not the proportions. Both MDA and MDG are unitless. For MDA, it is measured as the ratio of correct classification to total records. For MDG, it is the measurement of the cleanliness of the split. There is no cutoff range for determining MDA and MDG values [29,30]. We selected variables with higher MDA and MDG indicating the importance of the variables to our outcomes (active caries and caries experience). The selection of questionnaire items based on both MDA and MDG led to the classification that was most accurate and robust. $\mathrm{R}$ statistics was used for RF analyses.

Figures 1 and 2 show the list of questionnaire items on the $y$-axis and the importance on the $x$-axis. The longer bar indicates the more important the question is to the outcome variable.

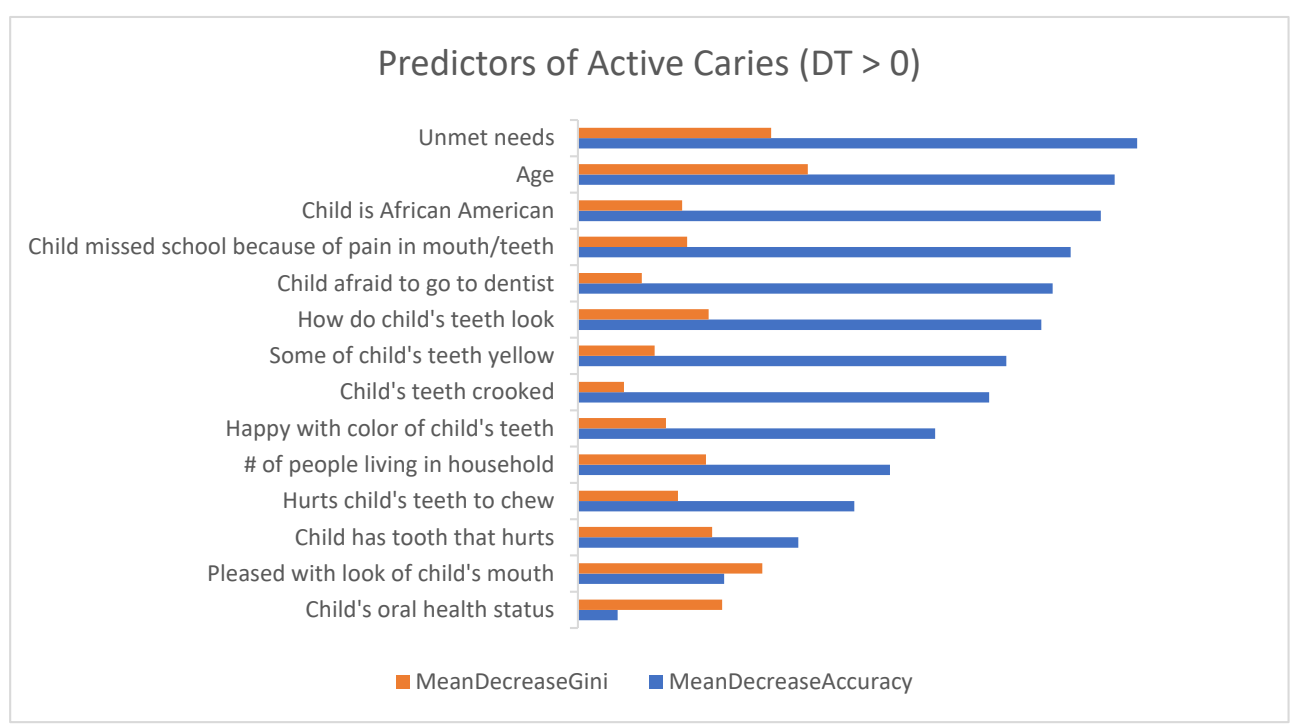

Figure 1. Demographic and oral health-related predictors of active caries (DT $>0$ ) showing both the mean decreasing of Gini (MDG) and mean decreasing of accuracy (MDA) measures. The higher the MDG and MDA, the more important the variables.

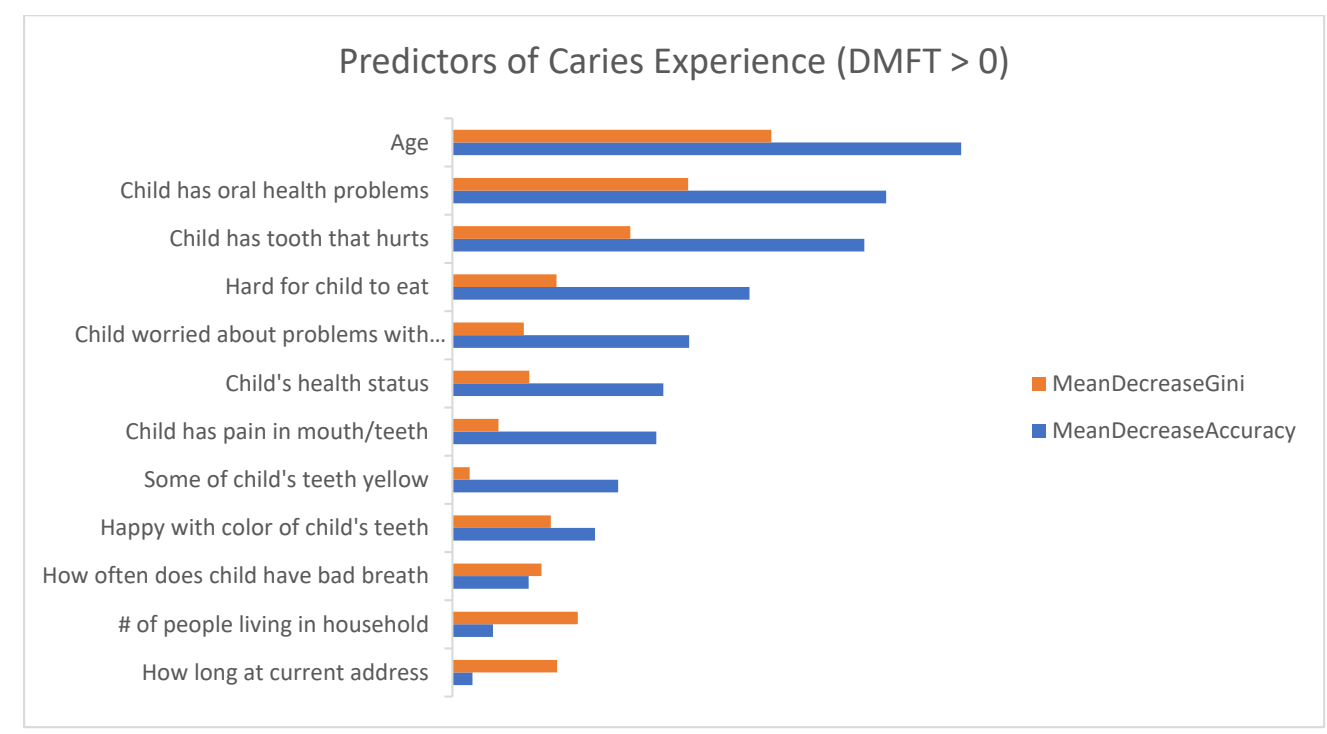

Figure 2. Demographic and oral health-related predictors of caries experience (DMFT $>0$ ) showing both the mean decreasing of Gini (MDG) and mean decreasing of accuracy (MDA) measures. The higher the MDG and MDA, the more important the variables. 


\section{Results}

\subsection{Sample Characteristics}

The descriptive statistics for the demographics, outcome variables and oral healthrelated predictor variables are presented in Table 2 . The majority of parents/caregivers were female $(n=126 ; 69 \%), 33$ to 44 years of age $(n=115 ; 63 \%)$ and Hispanic/Latino $(n=71 ; 39 \%)$, Caucasian/White $(n=45 ; 24 \%)$, Asian $(n=21 ; 11 \%)$ and African American $(n=14 ; 8 \%)$. Approximately half the children were between the ages of 2 and $4(n=76$; $42 \%)$. Parents identified their child's race/ethnicity as: Hispanic/Latino $(n=71 ; 39 \%)$, Caucasian/White $(n=43 ; 24 \%)$, Asian $(n=21 ; 12 \%)$, African American $(n=14 ; 7 \%)$ and multi-racial $(n=21 ; 12 \%)$.

Table 2. Descriptive characteristics of main outcomes, demographics and oral health-related predictor variables $(n=182)$.

\begin{tabular}{|c|c|}
\hline Sample Characteristics & $n(\%)$ \\
\hline \multicolumn{2}{|l|}{ Main Outcome Variables } \\
\hline \multicolumn{2}{|l|}{ Active Caries } \\
\hline Yes & $23(13)$ \\
\hline No & $159(87)$ \\
\hline \multicolumn{2}{|l|}{ Caries Experience (DMFT) } \\
\hline Yes & $86(47)$ \\
\hline No & $96(53)$ \\
\hline \multicolumn{2}{|l|}{ Parent Demographics } \\
\hline \multicolumn{2}{|l|}{ Age, years } \\
\hline$<30$ & $42(23)$ \\
\hline $30-44$ & $115(63)$ \\
\hline$\geq 45$ & $25(14)$ \\
\hline \multicolumn{2}{|l|}{ Gender } \\
\hline Male & $56(31)$ \\
\hline Female & $126(69)$ \\
\hline \multicolumn{2}{|l|}{ Race/ethnicity } \\
\hline Caucasian/White & $45(24)$ \\
\hline African American & $14(8)$ \\
\hline Hispanic/Latino & $71(39)$ \\
\hline Asian & $21(11)$ \\
\hline Other & $31(18)$ \\
\hline \multicolumn{2}{|c|}{ Number of people in household } \\
\hline$\leq 3$ & $31(17)$ \\
\hline $4-5$ & $101(56)$ \\
\hline$\geq 6$ & $50(27)$ \\
\hline \multicolumn{2}{|c|}{ Number of years lived at current address } \\
\hline$\leq 1$ year & $33(18)$ \\
\hline$>1$ year $-\leq 5$ years & $82(45)$ \\
\hline$>5$ years $-\leq 10$ years & $36(20)$ \\
\hline$>10$ years & $31(17)$ \\
\hline Child's Demographics & \\
\hline
\end{tabular}


Table 2. Cont.

\begin{tabular}{|c|c|}
\hline Sample Characteristics & $n(\%)$ \\
\hline \multicolumn{2}{|l|}{ Age, years } \\
\hline 2 & $21(12)$ \\
\hline 3 & $25(14)$ \\
\hline 4 & $30(16)$ \\
\hline 5 & $22(12)$ \\
\hline 6 & $44(24)$ \\
\hline 7 & $40(22)$ \\
\hline \multicolumn{2}{|l|}{ Gender } \\
\hline Male & $93(51)$ \\
\hline Female & $89(49)$ \\
\hline \multicolumn{2}{|l|}{ Race/ethnicity } \\
\hline Caucasian/White & $43(24)$ \\
\hline African American & $14(7)$ \\
\hline Hispanic/Latino & $71(39)$ \\
\hline Asian & $21(12)$ \\
\hline Multi-racial & $21(12)$ \\
\hline Other & $12(6)$ \\
\hline \multicolumn{2}{|c|}{ Oral health-related predictor variables (survey questions) } \\
\hline \multicolumn{2}{|c|}{$\begin{array}{c}\text { In general, would you say your child's oral } \\
\text { health status is: }\end{array}$} \\
\hline Excellent/very good & $120(66)$ \\
\hline Good & $50(27)$ \\
\hline Fair/poor & $12(7)$ \\
\hline \multicolumn{2}{|c|}{$\begin{array}{l}\text { During the last } 12 \text { months, did your child have } \\
\text { an oral health problem? }\end{array}$} \\
\hline Yes & $55(30)$ \\
\hline No & $127(70)$ \\
\hline \multicolumn{2}{|c|}{$\begin{array}{l}\text { In the last } 4 \text { weeks, how much of the time were } \\
\text { you pleased or happy with the look of your } \\
\text { child's mouth, teeth, jaws or gums? }\end{array}$} \\
\hline Always/almost always & $149(82)$ \\
\hline Often/sometimes & $30(16)$ \\
\hline Almost never/never & $3(2)$ \\
\hline \multicolumn{2}{|c|}{$\begin{array}{l}\text { In the last } 4 \text { weeks, how much of the time did } \\
\text { your child have pain or discomfort with } \\
\text { his/her mouth, tongue, teeth, jaws or gums? }\end{array}$} \\
\hline Always/almost always & $0(0)$ \\
\hline Often/sometimes & $14(8)$ \\
\hline Almost never/never & $168(92)$ \\
\hline \multicolumn{2}{|c|}{ How often does your child have bad breath? } \\
\hline Always/almost always & $10(6)$ \\
\hline Often/sometimes & $91(50)$ \\
\hline Almost never/never & $81(44)$ \\
\hline
\end{tabular}


Table 2. Cont.

\begin{tabular}{|c|c|}
\hline Sample Characteristics & $n(\%)$ \\
\hline \multicolumn{2}{|l|}{ When I look at my child's teeth } \\
\hline They look fine & $119(66)$ \\
\hline They could look a little better & $48(26)$ \\
\hline They could look a lot better & $15(8)$ \\
\hline \multicolumn{2}{|c|}{$\begin{array}{c}\text { In the last } 4 \text { weeks, how much of the time was } \\
\text { your child worried or concerned about } \\
\text { problems with his/her mouth, tongue, teeth, } \\
\text { jaws or gums? }\end{array}$} \\
\hline Always/almost always & $1(1)$ \\
\hline Often/sometimes & $7(4)$ \\
\hline Almost never/never & $174(95)$ \\
\hline \multicolumn{2}{|l|}{ My child's mouth hurts } \\
\hline Always/almost always & $0(0)$ \\
\hline Often/sometimes & $9(5)$ \\
\hline Almost never/never & $173(95)$ \\
\hline \multicolumn{2}{|l|}{ My child has a tooth that hurts } \\
\hline Always/almost always & $1(1)$ \\
\hline Often/sometimes & $15(8)$ \\
\hline Almost never/never & $166(91)$ \\
\hline \multicolumn{2}{|l|}{ It hurts my child's teeth to chew } \\
\hline Always/almost always & $0(0)$ \\
\hline Often/sometimes & $7(4)$ \\
\hline Almost never/never & $175(96)$ \\
\hline \multicolumn{2}{|c|}{$\begin{array}{l}\text { It is hard for my child to eat because of pain in } \\
\text { his/her mouth }\end{array}$} \\
\hline Always/almost always & $0(0)$ \\
\hline Often/sometimes & $9(5)$ \\
\hline Almost never/never & $173(95)$ \\
\hline \multicolumn{2}{|c|}{$\begin{array}{l}\text { How happy are you with the color of your } \\
\text { child's teeth? }\end{array}$} \\
\hline Very much/quite a bit & $141(78)$ \\
\hline Somewhat & $24(13)$ \\
\hline A little bit/not at all & $17(9)$ \\
\hline \multicolumn{2}{|l|}{ Some of my child's teeth are yellow } \\
\hline Yes & $21(12)$ \\
\hline No & $161(88)$ \\
\hline \multicolumn{2}{|l|}{ My child's teeth are crooked } \\
\hline Yes & $15(8)$ \\
\hline No & $167(92)$ \\
\hline
\end{tabular}

During the past 12 months, was there a time that your child needed dental care, but did not get it?

Yes $8(4)$

No $174(96)$


Table 2. Cont.

\begin{tabular}{cc}
\hline Sample Characteristics & $n \mathbf{( \% )}$ \\
\hline $\begin{array}{c}\text { How much is your child afraid to go to a } \\
\text { dentist? }\end{array}$ & $97(53)$ \\
\hline Not at all & $76(42)$ \\
\hline A little bit/somewhat & $9(5)$ \\
\hline A great deal & \\
\hline $\begin{array}{c}\text { During the last school year, how many days of } \\
\text { school did your child miss because of pain in } \\
\text { his/her mouth, teeth, gums (if child goes to } \\
\text { school)? }\end{array}$ & $168(92)$ \\
\hline Never & $13(7)$ \\
\hline 1 to 3 days & $1(1)$ \\
\hline 4 days or more
\end{tabular}

Based on the clinical dental exam, $13 \%(n=23)$ of children had active caries and $47 \%$ $(n=86)$ had more than one caries experience based on the DMFT index.

\subsection{Questionnaire Items Predicting Active Caries}

Figure 1 presents the list of important questionnaire items for classifying children with active caries. The top 10 questionnaire items from the RF model that were the highest predictors of active caries (had the highest MDG and MDA) included: Parent's age $(\mathrm{MDG}=0.84 ; \mathrm{MDA}=1.97)$, unmet needs $(\mathrm{MDG}=0.71 ; \mathrm{MDA}=2.06)$, parents were pleased or happy with the look of their child's mouth/teeth/jaws/gums (MDG $=0.68$; MDA $=0.54)$, child's overall oral health status $(\mathrm{MDG}=0.53$; $\mathrm{MDA}=0.14)$, child has a tooth that hurts $(\mathrm{MDG}=0.50$; $\mathrm{MDA}=0.81)$, overall look of child's teeth $(\mathrm{MDG}=0.48$; MDA = 1.70), number of people living in the household (MDG =0.47; MDA =1.15), child missed school because of pain in mouth / teeth $(\mathrm{MDG}=0.40 ; \mathrm{MDA}=1.81)$, child is African American $(\mathrm{MDG}=0.38 ; \mathrm{MDA}=1.92)$ and child's teeth hurt when they chew $(\mathrm{MDG}=0.37$; $\mathrm{MDA}=1.02)$.

\subsection{Questionnaire Items Predicting Caries Experience (Based on DMFT Index)}

Figure 2 presents the list of important questionnaire items for classifying children with caries experience. The top 10 questionnaire items from the RF model that were the highest predictors of caries experience included: Parent's age (MDG $=2.97 ; \mathrm{MDA}=4.74)$, child had an oral health problem within past 12 months $(\mathrm{MDG}=2.20 ; \mathrm{MDA}=4.04)$, child had tooth that hurts (MDG $=1.65$; $\mathrm{MDA}=3.84$ ), number of people living in household (MDG =1.17; MDA $=0.38$ ), how long parent and child have lived at current address (MDG $=0.98$; MDA $=0.19$ ), hard for child to eat because of pain in his/her mouth $(\mathrm{MDG}=0.97$; MDA $=2.77)$, parent is happy with the color of their child's teeth $(\mathrm{MDG}=0.92 ; \mathrm{MDA}=1.33)$, how often child has bad breath $(\mathrm{MDG}=0.83 ; \mathrm{MDA}=0.71)$, child's overall health status (MDG $=0.72 ; \mathrm{MDA}=1.97$ ) and child worried about problems with teeth $/$ mouth $(\mathrm{MDG}=0.66$; MDA $=2.21$ ).

The accuracy, sensitivity and specificity for the RF algorithm's 3-fold cross-validation set for active caries and caries experience are $0.71,0.94$ and 0.68 for active caries and 0.71 , 0.78 and 0.64 for caries experience (Table 1 ).

\section{Discussion}

In this study, we used RF to identify questionnaire items that were predictors of active caries and caries experiences using the DMFT index among 2 to 7-year-old children. 
This is the most recent of multiple papers that develop oral health algorithms or tools which could be used by dentists, oral health researchers and professionals and public policy makers for oral health screening, program assessment, oral health evaluation and oral health management and policy planning $[14-18,26]$. The studies in this series on children between 8 and 17 years of age (where both parents and children completed the questionnaire) [14-18] showed similar predictors of oral health as we found in our study among children between 2 and 7 years of age (where only the parents completed the questionnaire). For example, the current study showed that dental appearance and aesthetics, such as being pleased/happy with the look of the child's teeth/mouth/gums and color of the child's teeth (tooth color, such as white, yellow or brown, is associated with oral hygiene and is considered a reflection on a person's ability to engage in selfcare) [17] were important predictors of dental caries among children between 2 and 7 years of age, similar to what was found in the study among children between 8 and 17 years of age [14-18]. Physical aspects of a child's mouth, such as the child having a tooth that hurts and the child having difficulty eating due to pain in the mouth/teeth were also important predictors of the presence of caries and overall oral health among children between 2 and 7 years of age, similar to what was found in the study among children between 8 and 17 years of age [14-18]. These findings indicate that oral health questionnaire items could be used by pediatric dentists and other oral health care professionals to predict the presence of caries and other oral health-related problems in children. Identifying key predictors of dental caries from machine learning algorithms also gives the clinician an opportunity to educate patients/caregivers on the importance of good oral hygiene behaviors and a healthy diet to preventing childhood caries since many of the questionnaire items focus on the prevention of childhood caries [31,32].

This study also showed that unmet needs and demographic characteristics such as parent's age, child's race (African American), number of people living in the household and how long the parent and child have lived at their current address were strong predictors of active caries and caries experience in children between 2 and 7 years of age. These findings indicate that socio-demographic factors are important predictors of active caries and caries experience, which is not surprising as factors such as race/ethnicity and family income (which can affect household structure) are known social determinants of health that are associated with oral health disparities resulting in dental caries and untreated dental caries $[2,5,6,8]$. Having this information will give dental professionals the opportunity to conduct a more in-depth caries risk assessment of their patients' oral health-related needs, which traditionally includes a combination of questions pertaining to caries-related biological, social and cultural predisposing risk factors, disease indicators and protective factors, and make appropriate referrals to social-related services, if needed [32].

The study had many limitations, mainly the small sample size $(n=182)$ and low percentage of children with active caries (13\%) which limited the identification of variables that were predictors of active caries. To adjust for this, we used the RF methodology which works well for non-linear and high-dimensional variable sets and has a good sensitivity and relative acceptable specificity. This study required parents/caregivers to complete a questionnaire about their young child's oral health which introduces different types of bias, such as social desirability bias and potential response bias if the respondent was a grandparent rather than a parent. While patient reported outcomes directly from children are the gold standard for questionnaire items, patient proxy reported outcomes by the parent/caregiver are useful when children are too young and do not yet have the cognitive ability to self-report $[15,22,33]$. Selection bias is also possible given that parents/caregivers were given monetary incentives to participate. Finally, this study was conducted with families who were recruited from dental clinics and practices that agreed to participate in the study and may not be generalizable to families who are not currently under dental care. 


\section{Conclusions}

Our findings demonstrate how the use of machine learning algorithms based on oral health surveys can help dental providers identify key predictors of dental caries in infants and young children. Once the key predictors of dental caries have been identified, dental providers can then include these items as part of their caries risk assessment and take the opportunity to educate their patients/caregivers on the importance of good oral hygiene behaviors. Additionally, the emerging trend of teledentistry and virtual homes will rely less on in-person routine preventive dental visits and more on having parents assess the current status of their children's teeth and oral health by asking them some key questions that are known to have high predictability for outcomes of interest such as active caries and caries experience. Thus, the development of algorithm "toolkits" that help dental professionals assess their patient's oral health could prove extremely useful for prevention of dental caries among children.

Author Contributions: F.R.-G. made the following contributions to the manuscript: (1) Conception and design of the study, (2) reviewing and revising manuscript for important intellectual content and (3) final approval of the version to be submitted. M.M. made the following contributions to the manuscript: (1) Conception and design of the study, (2) reviewing and revising manuscript for important intellectual content and (3) final approval of the version to be submitted. C.A.M. made the following contributions to the manuscript: (1) Conception and design of the study, (2) reviewing and revising manuscript for important intellectual content and (3) final approval of the version to be submitted. Y.W. made the following contributions to the manuscripts: (1) Involved with the conception and design of the study, acquisition of data, analysis and interpretation of data, (2) original draft preparation, (3) review and editing of manuscript and (4) final approval of the version to be submitted. J.J.K. made the following contributions to the manuscript: (1) Original draft preparation, (2) analysis and interpretation of data, (3) review and editing of manuscript and (4) final approval of the version to be submitted. D.X. made the following contributions to the manuscript: (1) Original draft preparation, (2) analysis and interpretation of data, (3) review and editing of the manuscript and (4) final approval of the version to be submitted. S.Y.L. made the following contributions to the manuscript: (1) Conception and design of the study and acquisition of data, (2) reviewing and revising manuscript for important intellectual content and (3) final approval of the version to be submitted. R.D.H. made the following contributions to the manuscript: (1) Conception and design of the study, (2) reviewing and revising manuscript for important intellectual content and (3) final approval of the version to be submitted. J.S. made the following contributions to the manuscript: (1) Conception and design of the study, (2) reviewing manuscript for important intellectual content and (3) final approval of the version to be submitted. J.J.C. made the following contributions to the manuscript: (1) Involved with the conception and design of the study, acquisition of data, analysis and interpretation of data, (2) critically reviewing and revising the article for important intellectual content and (3) final approval of the version to be submitted. H.L. made the following contributions to the manuscripts: (1) Involved with the conception and design of the study, acquisition of data, analysis and interpretation of data, (2) critically reviewing and revising the article for important intellectual content and (3) final approval of the version to be submitted. All authors have read and agreed to the published version of the manuscript.

Funding: This research was supported by a National Institute of Dental and Craniofacial Research/NIH grant to the University of California, Los Angeles (UCLA) (U01DE022648).

Institutional Review Board Statement: The study was conducted according to the guidelines of the Declaration of Helsinki, and approved by the Institutional Review Board of the University of California, Los Angeles, Office of the Human Research Protection Program (Institutional Review Board approval 13-001330).

Informed Consent Statement: Informed consent was obtained from all subjects involved in the study. To participate in the study, each family member provided active consent, as approved by the University of California, Los Angeles Institutional Review Board (approval \# 13-001330). All children gave consent to participate in the study. Moreover, each of their parents or guardians signed an informed consent form. 
Data Availability Statement: The data presented in this study are available on request from the corresponding author [F.R.-G.] or Principal Investigator [H.L.]. The data are not publicly available due to privacy and ethical issue.

Acknowledgments: We thank the families for their participation in the study, which contributes to the enhancement of the development of the oral health item bank. We also thank the field staff of the data collection and coordination sites.

Conflicts of Interest: The authors declare no conflicting interest.

\section{References}

1. Colak, H.; Dulgergil, C.T.; Dalli, M.; Hamidi, M.M. Early childhood caries update: A review of causes, diagnoses, and treatments. J. Nat. Sci. Biol. Med. 2013, 4, 29-38.

2. Anil, S.; Anand, P.S. Early childhood caries: Prevalence, risk factors, and prevention. Front. Pediatr. 2017, 5, 157. [CrossRef]

3. Pitts, N.B.; Zero, D.T.; Marsh, P.D.; Elkstrand, K.; Weintraub, J.A.; Ramos-Gomez, F.; Tagami, J.; Twetman, S.; Tsakos, G.; Ismail, A. Dental caries. Nat. Rev. Dis. Primers 2017, 3, 17030. [CrossRef] [PubMed]

4. Hoeft, K.S.; Barker, J.C.; Shiboski, S.; Pantoja-Guzman, E.; Hiatt, R.A. Effectiveness evaluation of Contra Caries Oral Health Education Program for improving Spanish-speaking parents' preventive oral health knowledge and behaviors for their young children. Community Dent. Oral Epidemiol. 2016, 44, 564-576. [CrossRef] [PubMed]

5. World Health Organization. Dental caries: Key Facts. 2020. Available online: https://www.who.int/news-room/fact-sheets/ detail/oral-health (accessed on 13 November 2021).

6. Peres, M.A.; Macpherson, L.; Weyent, R.J.; Daly, B.; Venturelli, R.; Mathur, M.R.; Listl, S.; Celeste, R.K.; Guarnizo-Herreno, C.C.; Kearns, C.; et al. Oral diseases: A global public health challenge. Lancet 2019, 394, 249-260. [CrossRef]

7. Hoeft, K. Using community participation to assess acceptability of "Contra Caries", a theory- based, promotora-led oral health education program for rural Latino parents: A mixed methods study. BMC Oral Health 2015, 15, 103-114. [CrossRef] [PubMed]

8. Centers for Disease Control and Prevention. Disparities in Oral Health. 2021. Available online: https://www.cdc.gov/oralhealth/ oral_health_disparities/index.htm (accessed on 13 November 2021).

9. Fleming, E.; Afful, J. Prevalence of Total and Untreated Dental Caries among Youth: United States, 2015-2016. Available online: https:/ / www.cdc.gov/nchs/data/databriefs/db307.pdf (accessed on 13 November 2021).

10. Naavaal, S.; Kelekar, U. School hours lost due to acute/ unplanned dental care. Health Behav. Policy Rev. 2018, 5, 66-73. [CrossRef]

11. Barker, J.C.; Horton, S.B. An ethnographic study of Latino preschool children's oral health in rural California: Intersections among family, community, provider and regulatory sectors. BMC Oral Health 2008, 31, 8. [CrossRef] [PubMed]

12. Quock, R.L. The Evidence Supporting Fluoride Varnish. 2017. Available online: https://decisionsindentistry.com/article/ evidence-supporting-fluoride-varnish/ (accessed on 13 November 2021).

13. Bhanushali, P.; Katge, F.; Deshpande, S.; Chimata, V.K.; Shetty, S.; Pradhan, D. COVID-19: Changing trends and its impact on future of dentistry. Int. J. Dent. 2020, 2020, 1-6. [CrossRef] [PubMed]

14. Marcus, M.; Wang, Y.; Xiong, D. Child and parent demographic characteristics and oral health perceptions associated with clinically measured oral health. JDR Clin. Transl. Res. 2018, 3, 302-313. [CrossRef]

15. Liu, H.; Hays, R.D.; Marcus, M.; Coulter, I.; Maida, C.; Ramos-Gomez, F.; Shen, J.; Wang, Y.; Spolsky, V.; Lee, S.; et al. Patientreported oral health outcome measurement for children and adolescents. BMC Oral Health 2016, 16, 1-9. [CrossRef]

16. Wang, Y.; Hays, R.D.; Marcus, M.; Maida, C.A.; Shen, J.; Xiong, D.; Coulter, I.D.; Lee, S.Y.; Spolsky, V.W.; Crall, J.J.; et al. Developing children's oral health assessment tool kits using machine learning algorithm. JDR Clin. Transl. Res. 2019, 11, 233-243.

17. Maida, C.A.; Marcus, M.; Hays, R.D.; Coulter, I.D.; Ramos-Gomez, F.; Lee, S.Y.; McClory, P.S.; Van, L.V.; Wang, Y.; Shen, J.; et al. Child and adolescent perceptions of oral health over the life course. Qual. Life Res. 2015, 24, 2739-2751. [CrossRef] [PubMed]

18. Maida, C.A.; Marcus, M.; Hays, R.D.; Coulter, I.D.; Ramos-Gomez, F.; Lee, S.Y.; McClory, P.S.; Van, L.V.; Wang, Y.; Shen, J.; et al. Qualitative methods in the development of a parent survey of children's oral health status. J. Patient-Rep. Outcomes $2018,2,7$. [CrossRef] [PubMed]

19. Walsh, T.R.; Irwin, D.E.; Meier, A.; Varni, J.W.; DeWalt, D.A. The use of focus groups in the development of the PROMIS pediatrics item bank. Qual. Life Res. 2008, 17, 725-735. [CrossRef] [PubMed]

20. Varni, J.W.; Seid, M.; Rode, C.A. The PedsQL (TM): Measurement model for the pediatric quality of life inventory. Med. Care 1999, 37, 126. [CrossRef]

21. Matza, L.S.; Patrick, D.L.; Riley, A.W.; Alexander, J.J.; Rajmil, L.; Pleil, A.M.; Bullinger, M. Pediatric patient-reported outcome instruments for research to support medical product labeling: Report of the ISPOR PRO good research practices for the assessment of children and adolescents task force. Value Health 2013, 16, 461-479. [CrossRef] [PubMed]

22. Irwin, D.E.; Varni, J.W.; Yeatts, K.; DeWalt, D.A. Cognitive interviewing methodology in the development of a pediatric item bank: A patient reported outcomes measurement information system (PROMIS) study. Health Qual. Life Outcomes 2009, 7, 1-10. [CrossRef] [PubMed]

23. Koch, A.L.; Gershen, J.A.; Marcus, M. Children's oral health status index based on dentists' judgment. JADA 1985, 110, 36-42. [CrossRef] 
24. Von Elm, E.; Altman, D.G.; Egger, M.; Pocock, S.J.; Gotzsche, P.C.; Van denbroucke, J.P.; Strobe Initiative. The strengthening the reporting of observational studies in epidemiology (STROBE) statement: Guidelines for reporting observational studies. J. Clin. Eipdemiol. 2008, 61, 344-349. [CrossRef] [PubMed]

25. STROBE: Strengthening the Reporting of Observational Studies in Epidemiology. Available online: https://www.strobestatement.org/ (accessed on 14 November 2021).

26. Marcus, M.; Xiong, D.; Wang, Y.; Maida, C.A.; Hays, R.D.; Coulter, I.D.; Spolsky, V.W.; Lee, S.Y.; Shen, J.; Crall, J.J.; et al. Development of toolkits for detecting dental caries and caries experience among children using self-report and parent report. Community Dent. Oral Epidemiol. 2019, 47, 520-527. [CrossRef]

27. Cicchetti, D.V.; Feinstein, A.R. High agreement but low kappa: II. Resolving the paradoxes. J. Clin. Epidemiol. 1990, 43, 551-585. [CrossRef]

28. Calle, M.L.; Urrea, V. Letter to the editor: Stability of random forest importance measures. Brief. Bioinform. 2011, 12, 86-89. [CrossRef] [PubMed]

29. Kelleher, J.D.; Mac Namee, B.; D’arcy, A. Fundamentals of Machine Learning for Predictive Data Analytics: Algorithms, Worked Examples, and CAE Studies; MIT Press: Cambridge, MA, USA, 2015.

30. Yap, B.W.; Rani, K.A.; Rahman, H.A.A.; Fong, S.; Khairudin, Z.; Abdullah, N. An application of oversampling, undersampling, bagging and boosting in handling imbalanced datasets. In Proceedings of the First International Conference on Advanced Data and Information Engineering; Springer: Singapore, 2014; pp. 13-22.

31. Pitts, N.B.; Baez, R.J.; Diaz-Guillory, C.; Donly, K.J.; Feldens, C.A.; McGrath, C.; Phantumvanit, P.; Seow, W.K.; Sharkov, N.; Songpaisan, Y.; et al. Early Childhood Caries: IAPD Bangkok Declaration. J. Dent. Child. 2019, 86, 72.

32. Hurlbutt, M. CAMBRA: Best Practices in Dental Caries Management. 2011. Available online: https://pdfs.semanticscholar.org/ f6ac/6833549fe10821f8baa6bb927e19bcfa8591.pdf (accessed on 21 October 2021).

33. Wang, Y.; Hays, R.; Marcus, M.; Maida, C.; Shen, J.; Xiong, D.; Lee, S.; Spolsky, V.; Coulter, I.; Crall, J.; et al. Development of a parent's short form survey of their children's oral health. Int. J. Paediatr. Dent. 2019, 29, 332-344. [CrossRef] [PubMed] 